\title{
The impact of social support on the health-related quality of life of adult patients with tuberculosis in Harare, Zimbabwe: a cross-sectional survey
}

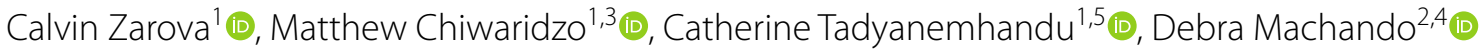 \\ and Jermaine M. Dambi ${ }^{1,3^{*}}$ (1)
}

\begin{abstract}
Objective: Tuberculosis (TB) is the second prime cause of mortality in Sub-Saharan Africa and remains a major worldwide public health problem. Unfortunately, patients with TB are at risk of poor mental health. However, patients who receive an adequate amount of social support are likely to have improved health outcomes. The study was done to establish how social support influences the health-related quality of life (HRQoL) of patients with TB in Harare, Zimbabwe. Data were collected from 332 TB patients and were analysed through structural equation modelling.

Results: The mean age of the participants was 40.1 (SD 12.5) years and most were; males (53\%), married (57.8\%), educated (97.3\%), unemployed (40.7\%), stayed with family (74.4\%), and reported of less than average levels of income (51.5\%). Patients received the most significant amount of social support from the family. Patients also presented with lower HRQoL as they considerably reported of pain, anxiety and depression. The final model accounted for $68.8 \%$ of the variance. Despite methodological limitations, the study findings suggest that social support optimises patients' HRQoL. Based on the patients' responses, it was noted that patients presented with lower mental health, therefore, there is a need to develop and implement patient wellness interventions.
\end{abstract}

Keywords: Tuberculosis, Social support, Health-related quality of life, Mental health, Zimbabwe

\section{Introduction}

Tuberculosis (TB) is the second prime cause of mortality in Sub-Saharan Africa and remains a major worldwide public health problem despite the discovery of highly effective drugs and vaccines $[1,2]$. The HIV/AIDS pandemic further exacerbates the burden of TB. For example, $23.1 \%$ of patients diagnosed with HIV/AIDS in SubSaharan Africa are reportedly co-infected with TB $[1,3]$. Unfortunately, patients with TB are at risk of poor mental health and lower health-related quality of life (HRQoL) [4]. For instance, between 40 and $70 \%$ of patients with

\footnotetext{
*Correspondence: jermainedambi@gmail.com; dmbjer001@myuct.ac.za ${ }^{1}$ Department of Rehabilitation, College of Health Sciences, University of Zimbabwe, P.O Box A178, Avondale, Harare, Zimbabwe

Full list of author information is available at the end of the article
}

TB suffer from various common mental disorders such as depression and anxiety [4-6].

Regrettably, patients with poor mental health are unlikely to adhere to treatment regimens, and this decreases treatment efficacy [6, 7]. Further, non-compliance leads to the development of drug-resistant TB which is expensive to treat and has an increased mortality rate [8]. Therefore, poor mental health perpetuates a vicious cycle of adverse health outcomes $[5,6]$. However, there is established evidence showing that patients who receive an adequate amount of social support (SS) are likely to have optimal mental health outcomes such as lower psychiatric morbidity [9] and increased HRQoL [10]. Social support is defined as the amount of both perceived and actual care received from family, friends and or the community [11]. Furthermore, SS is an essential buffer to 
adverse life events (e.g. diagnosis of TB), and higher SS leads to increased treatment adherence and improved treatment outcomes $[12,13]$. Logically, it can be hypothesised therefore that SS may improve HRQoL of patients with adverse life events such as TB. Unfortunately, there is a lack of evidence on the mental health of TB patients residing in low resource settings such as Zimbabwe, yet the burden of the disease is quite high. The present study, therefore, sought to establish how SS influences the HRQOL of patients with TB in Harare, Zimbabwe.

\section{Main text \\ Study design, research setting and participants}

A descriptive, cross-sectional study was carried out on adult patients with TB in Harare, Zimbabwe. Participants were conveniently recruited from one low-density suburb primary care clinic and two infectious disease hospitals. These three settings were selected as they have the highest catchment of patients with TB of varying socioeconomic status. Applying the following parameters; TB prevalence rate of $28.2 \%(\mathrm{p}=0.282$ and $\mathrm{q}=0.718)$ [2], $95 \%$ confidence interval, and expected $10 \%$ incomplete records, the minimum sample size according to STATISTICA software was 347. We recruited patients; with a confirmed diagnosis of TB according to doctor's notes, aged $\geq 18$ years, fluent in either English or Shona (a Zimbabwean native language) and had no other chronic comorbid conditions like HIV/AIDS, among others.

\section{Study instruments}

Social support and HRQoL were measured using the Multidimensional Scale of Perceived Social Support (MSPSS) and the EQ-5D, respectively. The MSPSS is a 12-item outcome which measures the amount of SS received from family, friends and significant other [14]. The MPSSS-Shona version is rated on a five-point Likert scale with responses ranging from strongly disagree $=1$ to strongly agree $=5$, and the scores are interpreted, the higher the score, the more significant the SS [15]. The EQ-5D is a generic HRQoL measuring participant' perceived HRQoL in the following five-domains: mobility, self-care, usual activities, pain, and anxiety/depression [16]. The severity of impairments is rated on a three Likert-scale, i.e. no problem, some problem and extreme problem. The responses are log-transformed to give a utility score which ranges from zero to one, a score of one presenting perfect health status. Respondents also rate their health on a linear visual analogue scale which has a score range of $0-100$ and the higher the score, the higher the HRQoL $[16,17]$. The MSPSS and EQ-5D were selected for the present study as they; are standardised, generic outcomes with robust psychometrics, very brief, and have been translated and validated into Shona [14-17].

\section{Procedure}

Institutional and ethical approval for the study was granted by the City of Harare Health Council and the Joint Research and Ethics Committee for the University of Zimbabwe, College of Health Sciences \& Parirenyatwa Group of Hospitals (Ref: JREC/362/17). This study adhered to the Declaration of Helsinki ethical principles. Participants were approached as they were waiting for services at the respective research sites, and recruitment was done over 4 consecutive weeks. The principal researcher explained the study aims, and interested participants were requested to give written consent before participating. The questionnaires were self-administered to identified participants, and completed questionnaires were collected on the same day.

\section{Data analysis and management}

Data were entered into Microsoft Excel and analysed using SPSS (version 23), STATISTICA (version 14) and STATA (Version 15). Normality was checked using the Shapiro-Wilk Test and; participants characteristics, EQ-5D and MSPSS outcomes were summarised using descriptive statistics. Correlation co-efficiencies, Chi square/Fishers' exact tests, analysis of variance (ANOVA) and $\mathrm{t}$-tests were used to determine factors influencing patients' social support and HRQoL. Subsequently, patients characteristics (age, marital status, educational level, employment status, perceived financial status and place of residence) and MSPSS and EQ-5D were entered in the structural equation model (SEM) as endogenous and exogenous variables, respectively. The following parameters were set as a minimum criterion for model fit; Likelihood Ratio Chi squared Test $\left(\chi m s^{2}\right)$-criteria value $p>0.05$, Root Mean Square Error of Approximation (RMSEA) - criteria value $\leq 0.06$, Comparative Fit Index (CFI) - criteria value $\geq 0.90$, Tucker-Lewis Index (TLI) criteria value $\geq 0.90$ and the Standardized Root Mean Square Residual (SRMR)—criteria value $\leq 0.06[18,19]$.

\section{Results}

The mean age of the participants was 40.1 (SD 12.5) years. Most patients were; males (53\%), married (57.8\%), educated (97.3\%), unemployed (40.7\%), stayed in highdensity suburbs $(46.4 \%)$, stayed in rented accommodation (44.9\%), stayed with family (74.4\%), and reported of less than average levels of income (51.5\%). Further, as shown in Table 1, patients received the least and highest amount of social support from friends [(mean 2.8 (SD 1.2)] and family [(Mean 3.7 (SD 1.0)], respectively, and frequencies of MSPSS responses are shown in Additional 
Table 1 Participants characteristics, $\mathbf{N}=332$

\begin{tabular}{|c|c|c|}
\hline Variable & Attribute & Frequency, $n$ (\%) \\
\hline \multirow[t]{2}{*}{ Gender } & Males & $176(53.0)$ \\
\hline & Females & $156(47.0)$ \\
\hline Age & Mean $(S D)^{\mathrm{a}}$ & $40.1(12.5)$ \\
\hline \multirow[t]{4}{*}{ Marital status } & Divorced & $27(8.1)$ \\
\hline & Widowed & $43(13.0)$ \\
\hline & Single & $113(34.0)$ \\
\hline & Married & $192(57.8)$ \\
\hline \multirow[t]{3}{*}{ The highest level of education } & Primary education & $58(17.5)$ \\
\hline & Secondary education & $217(65.4)$ \\
\hline & Tertiary education & $57(17.2)$ \\
\hline \multirow[t]{4}{*}{ Employment status } & Unemployed & $135(40.7)$ \\
\hline & Retired & $15(4.5)$ \\
\hline & Self-employed & $105(31.6)$ \\
\hline & Formally employed & $77(23.2)$ \\
\hline \multirow[t]{3}{*}{ Place of residence } & High-density suburb & $154(46.4)$ \\
\hline & Medium density suburb & $94(28.3)$ \\
\hline & Low-density suburb & $84(25.3)$ \\
\hline \multirow[t]{5}{*}{ Perceived level of income } & Very inadequate & $71(21.4)$ \\
\hline & Inadequate & $100(30.1)$ \\
\hline & Neutral & $107(32.2)$ \\
\hline & Adequate & $47(14.2)$ \\
\hline & Very adequate & $7(2.1)$ \\
\hline \multirow[t]{4}{*}{ House ownership } & Owner & $114(34.3)$ \\
\hline & Rent & $149(44.9)$ \\
\hline & Company & $21(6.3)$ \\
\hline & Family house & $48(14.5)$ \\
\hline \multirow[t]{4}{*}{ Persons staying with } & Alone & $26(7.8)$ \\
\hline & Friends & $5(1.5)$ \\
\hline & Family & $250(75.3)$ \\
\hline & Relatives & $51(15.4)$ \\
\hline \multirow[t]{4}{*}{ MSPSS scores } & Friends subscale: mean (SD) ${ }^{\mathrm{a}}$ & $2.8(S D$ 1.2) \\
\hline & Significant other subscale: Mean (SD) ${ }^{\mathrm{a}}$ & $3.5($ SD 1.1) \\
\hline & Family subscale: mean (SD) ${ }^{a}$ & 3.7 (SD 1.0) \\
\hline & Summative scores: Mean (SD) ${ }^{\mathrm{a}}$ & 39.7 (SD 10.6) \\
\hline \multirow[t]{2}{*}{ EQ-5D scores } & Utility scores: mean (SD) ${ }^{\mathrm{a}}$ & 0.672 (SD 0.238) \\
\hline & VAS scores: mean (SD) ${ }^{\mathrm{a}}$ & 51 (SD 18.1) \\
\hline
\end{tabular}

a Data not presented in the $\mathrm{n}(\%)$ format

file 1. Patients considerably reported of pain, anxiety and depression (see Additional file 2 for frequencies of EQ-5D responses), and the mean HRQoL (EQ-5D-VAS) score was 51 (SD 18.1).

The final model (Fig. 1) revealed that patients who received an adequate amount of SS had optimal/greater HRQoL, $r=0.33, p<0.001$. Further; increased age, being unmarried, lower education attainment, lower SES and residing in urban areas were associated with poorer mental health. The model displayed adequate fit, except for the Likelihood ratio, most of the goodness of fit indices were within the acceptable thresholds (see Table 2), and the model accounted for $68.8 \%$ of the variance (see Additional file 3).

\section{Discussion}

The main finding of the present study was that patients who received an adequate amount of social support had optimal/greater HRQoL and this is congruent with previous studies $[4,9,20]$. However, patients reported lower 


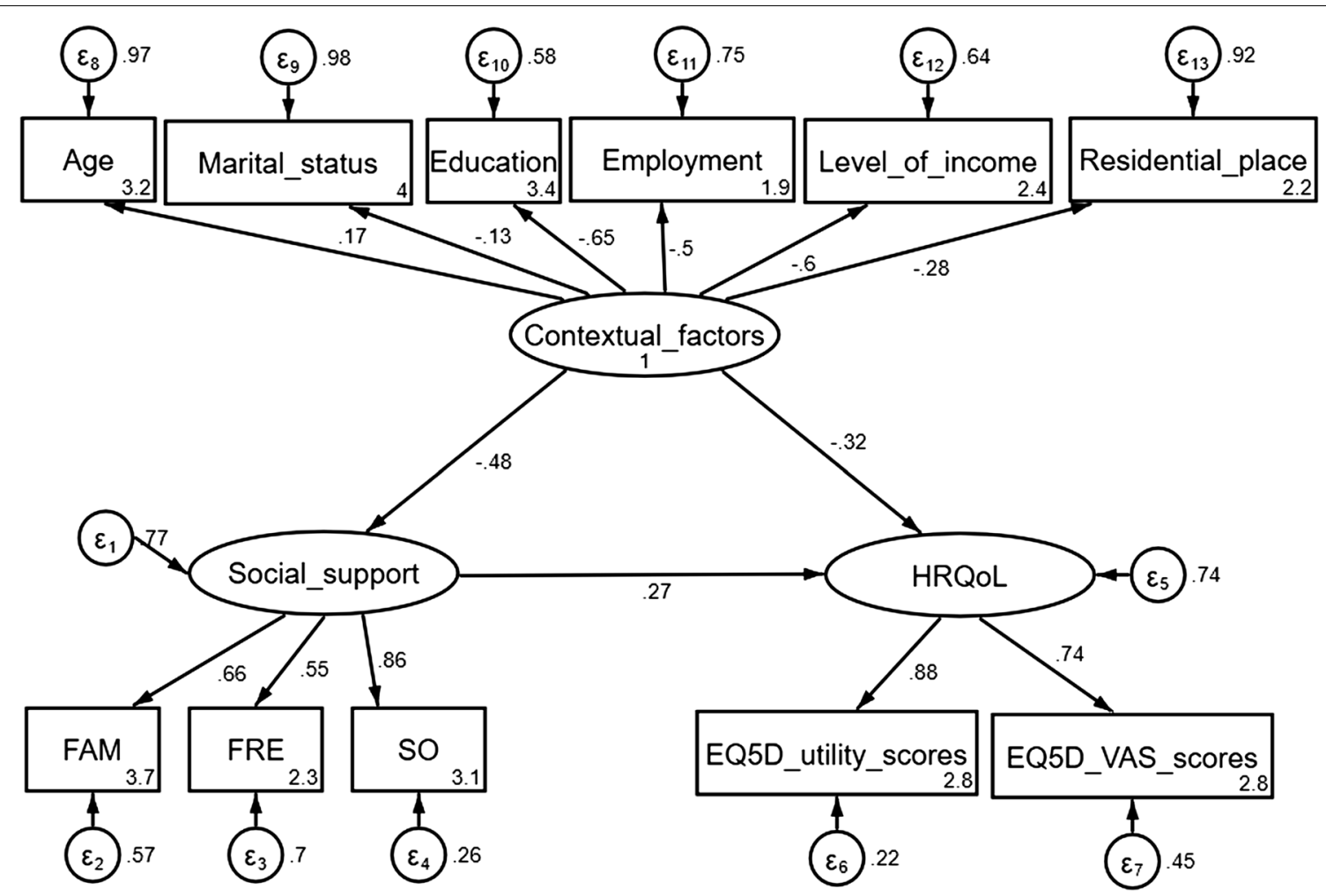

Fig. 1 Patients' mental health model showing the relationship between patients perceived levels of social support, HRQoL and contextual factors

Table 2 Model fit indices

\begin{tabular}{|c|c|c|c|}
\hline Fit statistic & Index & Criterion for fit & Result-interpretation \\
\hline \multirow[t]{2}{*}{ Likelihood ratio } & Chi squared test $\left(x m s^{2}\right)$ & $p>0.05$ & $x^{2}(\mathrm{df} 41)=107.29, p<0.001$-misfit \\
\hline & Normed Chi square $\left[x^{2} / d f\right]$ & $x^{2} / d f<2$ & 2.6-misfit \\
\hline Population error & Root mean squared error of approximation (RMSEA)- $(90 \% \mathrm{Cl})$ & RMSEA $\leq 0.06$ & $0.060(0.026: 0.080)$ —slight misfit \\
\hline \multirow[t]{2}{*}{ Information criteria } & Akaike's information criterion (AIC) & The smaller, the better & 12,214.5-best fit \\
\hline & Bayesian information criterion (BIC) & The smaller, the better & 12,351.5-best fit \\
\hline \multirow[t]{2}{*}{ Baseline comparison } & Comparative Fit Index (CFI) & $C F I \geq 0.90$ & 0.904 -good fit \\
\hline & Tucker-Lewis Index (LFI) & $\mathrm{LFI} \geq 0.90$ & 0.871 - a slight misfit \\
\hline \multirow[t]{2}{*}{ Size of residuals } & Standardized root mean squared residual (SRMR) & $S R M R \leq 0.08$ & 0.060 -good fit \\
\hline & The coefficient of determination (SD) & The greater, the better & 0.7 -good fit \\
\hline
\end{tabular}

HRQoL (mean EQ-5D VAS - 51 (SD 18.1) when compared to that of healthy urban-dwellers residing in the same research setting who previously reported a mean score of 77.5 (SD 17.4) [17]. The HRQoL outcomes were however almost like those of Zimbabwean patients with HIV/AIDS [21] which demonstrates the impact of long-term conditions on patients' HRQoL. Invariably, pathological process/changes, e.g. persistent coughing, peripheral neuropathy, haemoptysis, fatigue and chest pain, and medication side effects such as excessive tingling sensations have been reported to contribute highly towards lower HRQoL [4, 22].

Additionally, external/environmental factors such as cultural beliefs/myths and stigma are also likely to contribute towards depression, lower self-efficacy, and lower emotional well-being which ultimately results in lower HRQoL [1, 7, 23, 24]. Evidence from a systematic review evaluating the HRQoL of South African patients with TB suggests that psycho-social burden, e.g. isolation and stigma dramatically impact patients' HRQoL when 
compared to the effects of clinical symptoms [25]. This is unfortunate given that stigma precludes patients from receiving an adequate amount of SS [7, 23, 25]. Several studies concur that patients with more magnificent SS are likely; to promptly initiate diagnosis and treatment [24], comply with treatment regimens [12,13], and have lower psychiatric morbidity [9] which will, in turn, leads to an increased HRQOL [4].

Discrepancies in the amount of SS received from family and friends is suggestive of societal stigma and or cultural influences. For instance, in the African context, it is often the responsibility of the immediate family and spouses to care for a sick relative [1]. This could explain differences in SS sources as most participants were married. Further, the present study also demonstrated the impact of contextual factors on caregivers' mental health as reported elsewhere $[5,20,26]$. For example, patients who were; educated, formally employed and had higher levels of income had higher levels of SS and HRQoL. Patients with more financial resources are likely to afford specialist support services and likely to use medications with fewer side-effects and are thus likely to have higher HRQoL [27]. This sharply contrasts with more impoverished patients who are likely to develop anxiety and or depression because of financial pressure [24, 28]. Malnutrition and non-compliance to treatment regimens, e.g. medication intake, failure to attend scheduled follow-up appointments and lack of funds for purchasing drugs and investigative tests have been previously reported in patients residing in low-resource settings $[1,7,24,27$, 28].

\section{Conclusion}

The current study suggests that TB patients who receive a higher amount of social support are likely to have higher HRQoL in the Zimbabwean context. Also, given that patients reported lower mental health, there is a need to develop and implement patient wellness interventions. Further studies should utilise longitudinal and qualitative study designs and recruit patients residing in rural areas to understand the mental health of Zimbabwean patients with TB fully. Efforts should also be made to validate mental health outcomes in this population formally.

\section{Limitations}

Although this the first large-scale study to evaluate the impact of SS on the HRQOL of tuberculosis patients in Zimbabwe the study outcomes need to be interpreted with caution given the following limitations:

- Participants and the research settings were conveniently selected. However, the setting represents the largest catchment areas of patients with $\mathrm{TB}$ in Harare.

- The duration of TB diagnosis and treatment were not extracted, and these may have influenced the reported mental health.

- Participants were only recruited from an urban setting thus outcomes may not be generalisable to all Zimbabwean patients given that more than $67 \%$ of Zimbabweans reside in rural areas [29].

- We only recruited participants who were proficient in either English and or Shona languages; Zimbabwe is a multilinguistic country. However, the study instruments were only adapted, translated and validated in the Shona language.

- The psychometric properties of the study instruments were not formally tested in patients with TB.

- Although we applied SEM, causality could not be inferred given the cross-sectional nature of the data.

- Confounding variables such as the length of treatment duration, type of $\mathrm{TB}$, amongst others were not documented, and this may partly account for the $31.2 \%$ of the variance which was not explained by the final model.

\section{Additional files}

Additional file 1. Frequencies of responses on the MSPSS, $N=332$. Table denotes frequencies of responses on the MSPSS, a 12-item social support outcome measure. Responses are rated on a five-point Likert scale, ranging from strongly disagree $=1$ to strongly agree $=5$.

Additional file 2. Frequencies of responses on the EQ-5D, $N=332$. Table denotes frequencies of responses on the EQ-5D, a generic health-related quality of life measure. Respondents indicate whether they had problems in with self-care, usual activities, mobility, pain/discomfort and anxiety/ depression on a three-adjunct scale. Responses are rated as "no problem", "some problem" and "extreme problem".

Additional file 3. Variance explained by the model. Table denotes the variance accounted by the variables and the total model expressing the relationship between contextual factors, levels of social support and health-related quality of life.

\section{Abbreviations}

ANOVA: analysis of variance; CFI: Comparative Fit Index; EQ-5D: EuroQol five-dimension scale; HIV/AIDS: human deficiency virus/acquired immunodeficiency syndrome; HRQoL: health-related quality of life; LTI: Tucker-Lewis Index; MSPSS: Multidimensional Scale of Perceived Social Support; RMSEA: Root Mean Square Error of Approximation; SD: standard deviation; SEM: structural equation model; SRMR: Standardized Root Mean Square Residual; SS: social support; TB: tuberculosis.

\section{Authors' contributions}

CZ, MC, CT and JMD developed the concept and design of the study. CZ collected the data and drafted the first version of the manuscript with the assistance of DM. JMD conducted the data analysis and statistical interpretation, extensively revised the first version of the manuscript, prepared all prerequisite processes for articles submission, submitted the manuscript 
and is the corresponding author. MC, CT and DM revised and contributed to the drafting/revision of the third and fourth versions of the manuscript in preparation for submission to the journal. All authors read and approved the final manuscript.

\section{Author details}

${ }^{1}$ Department of Rehabilitation, College of Health Sciences, University of Zimbabwe, P.O Box A178, Avondale, Harare, Zimbabwe. ${ }^{2}$ Department of Psychiatry, College of Health Sciences, University of Zimbabwe, P.O Box A178, Avondale, Harare, Zimbabwe. ${ }^{3}$ School of Health and Rehabilitation Sciences, Faculty of Health Sciences, University of Cape Town Observatory, Cape Town 7700, South Africa. ${ }^{4}$ Department of Psychology, University of Cape Town, Rondebosch, Cape Town 7701, South Africa. ${ }^{5}$ Department of Physiotherapy, School of Therapeutic Sciences, Faculty of Health Sciences, University of the Witwatersrand, Johannesburg, South Africa.

\section{Acknowledgements}

We would want to acknowledge participants for their invaluable participation especially. The data were collected as part of CZ's undergraduate thesis which JMD supervised him. Appreciation also goes to the AMARI consortium for various capacity building initiatives which facilitated the writing of the present manuscript. The manuscript is a product of the manuscript writing and systematic review workshops facilitated by Dr. Helen Jack (Harvard University/Kings College London). Further, the manuscript is also a practical application of the Academic Career Enhancement Series (ACES) program led by Dr. Christopher Merritt (Kings College London). The senior author utilized the skills acquired through the ACES program in both thesis supervision and mentoring of the first author in producing the first draft of the manuscript. Statistical skills learnt from the data analysis workshops by Dr. Lorna Gibson and Professor Helen Weiss (London School of Hygiene and Tropical Medicine) were also fundamental in enhancing the senior authors' statistical analysis and interpretation skills.

\section{Competing interests}

The authors declare that they have no competing interests.

\section{Availability of data and materials}

The datasets used and/or analysed during the current study are available from the corresponding author on reasonable request.

\section{Consent for publication}

Not applicable as the manuscript does not contain any data from any individual person.

\section{Ethics approval and consent to participate}

Ethical approval for the study was granted by the City of Harare Health Department and the Joint Research and Ethics Committee for the University of Zimbabwe, College of Health Sciences \& Parirenyatwa Group of Hospitals (Ref: JREC/362/17). Participants were treated as autonomous agents and were requested to sign written consent before participation. Pseudo-names were used to preserve confidentiality, data were stored securely, and only the researchers had access to the information gathered, and participants could voluntarily withdraw from the study at any time without any consequences.

\section{Funding}

The MSPSS was adapted, translated and validated into Shona as part of the senior authors' Ph.D. work at the University of Cape Town. The work is being funded by The African Mental Health Research Initiative (AMARI). AMARI is a consortium of four African universities whose overall goal is to build excellence in leadership, training and science amongst African scholars in mental, neurological and substance use (MNS) research in Ethiopia, Malawi, South Africa and Zimbabwe. AMARI, at the University of Zimbabwe College of Health Sciences (UZCHS), secured funding from the Wellcome Trust through the Developing Excellence in Leadership and Science (DELTAS) Africa initiative. The DELTAS Africa Initiative is an independent funding scheme of the African Academy of Sciences (AAS)'s Alliance for Accelerating Excellence in Science in Africa (AESA) and supported by the New Partnership for Africa's Development Planning and Coordinating Agency (NEPAD Agency) with funding from the Wellcome Trust [DEL-15-01] and the UK government. The views expressed in this publication are those of the author(s) and not necessarily those of AAS, NEPAD Agency, Wellcome Trust, or the UK government. The funding agency had no role in the design of the study and collection, analysis, interpretation of data, or in writing the manuscript.

\section{Publisher's Note}

Springer Nature remains neutral with regard to jurisdictional claims in published maps and institutional affiliations.

Received: 27 August 2018 Accepted: 1 November 2018

Published online: 06 November 2018

\section{References}

1. Cremers AL, Gerrets R, Kapata N, Kabika A, Birnie E, Klipstein-grobusch $\mathrm{K}$, et al. Tuberculosis patients' pre-hospital delay and non-compliance with a longstanding DOT programme : a mixed methods study in urban Zambia. BMC Public Health. 2016;16:1-11. https://doi.org/10.1186/s1288 9-016-3771-9.

2. World Health Organization. Global tuberculosis report 2017. 2017. www.who.int/tb/publications/global_report/gtbr2017_main_text.pdf. Accessed 15 Aug 2018.

3. Gao J, Zheng P, Fu H. Prevalence of TB/HIV co-infection in countries except China: a systematic review and meta-analysis. PLoS ONE. 2013:8(5):e64915.

4. Saleem S, Malik AA, Ghulam A, Ahmed J, Hussain H. Health-related quality of life among pulmonary tuberculosis patients in Pakistan. Qual Life Res. 2018;1:1. https://doi.org/10.1007/s11136-018-1954-9.

5. Bauer M, Leavens A, Schwartzman K. A systematic review and meta-analysis of the impact of tuberculosis on health-related quality of life. Qual Life Res. 2013;22:2213-35.

6. Doherty AM, Kelly J, McDonald C, O'Dywer AM, Keane J, Cooney J. A review of the interplay between tuberculosis and mental health. Gen Hosp Psychiatry. 2013;35:398-406.

7. Wynne A, Richter S, Jhangri GS, Alibhai A, Rubaale T, Wynne A, et al. Tuberculosis and human immunodeficiency virus : exploring stigma in a community in western Uganda. AIDS Care. 2014;26:940-6. https://doi. org/10.1080/09540121.2014.882488.

8. Murray EJ, Bond VA, Marais BJ, Godfrey-faussett P, Ayles HM, Beyers N. High levels of vulnerability and anticipated stigma reduce the impetus for tuberculosis diagnosis in Cape Town, South Africa. Health Policy Plan. 2013;28:410-8.

9. Simpson JSA, Carlson LE, Beck CA, Patten S. Effects of a brief intervention on social support and psychiatric morbidity in breast cancer patients. Psychooncology. 2002;11:282-94.

10. Pachi A, Bratis D, Moussas G, Tselebis A. Psychiatric morbidity and other factors affecting treatment adherence in pulmonary tuberculosis patients. Tuberc Res Treat. 2013;2013:1-37.

11. Li H, Ji Y, Chen T. The roles of different sources of social support on emotional well-being among Chinese elderly. PLOS ONE. 2014;9:1-8.

12. DiMatteo MR. Social support and patient adherence to medical treatment: a meta-analysis. Health Psychol. 2004;23:207-18.

13. Deshmukh RD, Dhande DJ, Sachdeva KS, Sreenivas AN, Kumar AMV, Parmar M. Social support a key factor for adherence to multidrug-resistant tuberculosis treatment. Indian J Tuberc. 2018;65:41-7.

14. Dambi J, Corten L, Chiwaridzo M, Jack H, Jelsma J, Mlambo T. A systematic review of the psychometric properties of the cross-cultural translations and adaptations of the Multidimensional Perceived Social Support Scale (MSPSS). Health Qual Life Outcomes. 2018;16:1-19. https://doi. org/10.1186/s12955-018-0912-0.

15. Dambi JM, Tapera L, Chiwaridzo M, Tadyanemhandu C, Nhunzvi C. Psychometric evaluation of the Shona version of the Multidimensional Scale of Perceived Social Support Scale (MSPSS-Shona) in adult informal caregivers of patients with cancer in Harare, Zimbabwe. Malawi Med J. 2017;29:89-96

16. Jelsma J, Hansen K, de Weerdt W, de Cock P, Kind P. How do Zimbabweans value health states? Popul Health Metr. 2003;1:11.

17. Jelsma J, Mhundwa K, De Weerdt W, De Cock W, Chivaura V. The Shona Version of the EQ-5D. Cent Afr J Med. 2001:47:8-13.

18. Green T. A methodological review of structural equation modelling in higher education research. Stud High Educ. 2016;41:2125-55. 
19. Cheung GW, Rensvold RB. Evaluating goodness-of-fit indexes for testing measurement invariance. Struct Equ Model. 2002;9:233-55.

20. Masumoto S, Yamamoto T, Ohkado A, Yoshimatsu S, Querri AG, Kamiya Y. Factors associated with health-related quality of life among pulmonary tuberculosis patients in Manila, the Philippines. Qual Life Res. 2014;23:1523-33.

21. Mafirakureva N, Dzingirai B, Postma MJ, van Hulst M, Khoza S. Healthrelated quality of life in HIV/AIDS patients on antiretroviral therapy at a tertiary care facility in Zimbabwe. AIDS Care. 2016:28:904-12.

22. Guo N, Marra F, Marra CA. Measuring health-related quality of life in tuberculosis: a systematic review. Health Qual Life Outcomes. 2009:7:1-10.

23. Courtwright A. Tuberculosis and stigmatization: pathways and interventions. Public Health Rep. 2010;125:34-42.

24. De Vries SG, Cremers AL, Heuvelings CC, Greve PF, Visser BJ, Bélard S, et al. Barriers and facilitators to the uptake of tuberculosis diagnostic and treatment services by hard-to-reach populations in countries of low and medium tuberculosis incidence: a systematic review of qualitative literature. Lancet Infect Dis. 2017;17:128-43.
25. Kastien-Hilka T, Abulfathi A, Rosenkranz B, Bennett B, Schwenkglenks M, Sinanovic E. Health-related quality of life and its association with medication adherence in active pulmonary tuberculosis-a systematic review of global literature with focus on South Africa. Health Qual Life Outcomes. 2016;14:42. https://doi.org/10.1186/s12955-016-0442-6.

26. Jaber AAS, Khan AH, Sulaiman SAS. Evaluating treatment outcomes and durations among cases of smear-positive pulmonary tuberculosis in Yemen: a prospective follow-up study. J Pharm Policy Pract. 2017;10:36.

27. Li CT, Chu KH, Reiher B, Kienene T, Chien LY. Evaluation of health-related quality of life in patients with tuberculosis who completed treatment in Kiribati. J Int Med Res. 2017:45:610-20.

28. Ali A, Jaber S, Khan AH, Azhar S, Sulaiman S, Ahmad N. Evaluation of health-related quality of life among tuberculosis patients in two cities in Yemen. PLoS ONE. 2016;11(6):e0156258.

29. Zimbabwe National Statistic Agency. Zimbabwe Population Census 2012. www.zimstat.co.zw/.../Census/CensusResults2012/National_Report.pdf. Accessed 15 Aug 2018.
Ready to submit your research? Choose BMC and benefit from:

- fast, convenient online submission

- thorough peer review by experienced researchers in your field

- rapid publication on acceptance

- support for research data, including large and complex data types

- gold Open Access which fosters wider collaboration and increased citations

- maximum visibility for your research: over 100M website views per year

At BMC, research is always in progress.

Learn more biomedcentral.com/submissions 